\title{
Influence of breastfeeding support on the tendencies of breastfeeding rates in the city of Pelotas (RS), Brazil, from 1982 to 2004
}

\author{
Elaine Albernaz, ${ }^{1}$ Cora L. Araújo, ${ }^{2}$ Elaine Tomasi, ${ }^{1}$ Gicele Mintem, ${ }^{2}$ \\ Elsa Giugliani, ${ }^{3}$ Alicia Matijasevich, ${ }^{2}$ Mercedes de Onis,${ }^{4}$ Fernando C. Barros, ${ }^{1}$ \\ Cesar G. Victora ${ }^{2}$
}

\begin{abstract}
Objective: To evaluate the influence of breastfeeding support on breastfeeding rates in the city of Pelotas (RS), Brazil.

Methods: The prevalence rates of exclusive breastfeeding and of overall breastfeeding were compared in four cohorts of children, born in 1982, 1993, 1997-1998 and 2004. The children selected for this study fulfilled the inclusion criteria for the WHO Multicenter Growth Reference Study, in order to afford comparison with the 1997-1998 cohort, which was made up of children selected for that study. The 1997-1998 cohort received systematic breastfeeding support.

Results: There was an increase in the rates of exclusive breastfeeding: from $26 \%$ at 1 month of age in 1993 to $77 \%$ at the same age in 2004, and from $16 \%$ at 3 months to $46 \%$ for the same dates, respectively. Breastfeeding rates at later ages exhibited a tendency to increase, although with less significance: from $15 \%$ in 1982 at 12 months to $34 \%$ in 2004 at the same age, and from $6 \%$ at 24 months to $14 \%$ for the same dates, respectively.
\end{abstract}

Conclusions: Breastfeeding support has contributed to a tendency for breastfeeding rates to increase.

J Pediatr (Rio J). 2008;84(6):560-564: Breastfeeding, health promotion, infant.

\section{Introduction}

Breastfeeding promotion is a priority, ${ }^{1}$ and several different studies have pointed out the importance of exclusive breastfeeding (EBF) during the first months of life. ${ }^{2,3}$ The United Nations Children's Fund (UNICEF) and the World Health Organization (WHO) recommend EBF until 6 months of age, ${ }^{4}$ when complementary foods should be introduced in combination with breastfeeding, which should be maintained until 2 years of age or more. ${ }^{5}$

A range of interventions are shown to increase breastfeeding rates. Individual support for nursing mothers contribute to this increase by preventing the premature introduction of complementary foods and increasing breastfeeding duration. ${ }^{6-8}$

Pelotas is a city in the state of Rio Grande do Sul, in Southern Brazil, and was a participating center in the Multicenter Growth Reference Study (MGRS). ${ }^{9}$ The objective of that study was to compile a new neonatal growth reference based on children with specific characteristics, such as being breastfed for at least 1 year, exclusively or predominately for the first 4-6 months of life, as recommended by WHO at the time. In order to increase the number of children who met these criteria, a breastfeeding support program was implemented. With the

1. Universidade Católica de Pelotas (UCPel), Pelotas, RS, Brazil.

2. Departamento de Medicina Social, Universidade Federal de Pelotas (UFPel), Pelotas, RS, Brazil.

3. Universidade Federal do Rio Grande do Sul (UFRGS), Porto Alegre, RS, Brazil.

4. World Health Organization (WHO), Geneva, Switzerland.

No conflicts of interest declared concerning the publication of this article.

Suggested citation: Albernaz E, Araújo CL, Tomasi E, Mintem G, Giugliani E, Matijasevich A, et al. Influence of breastfeeding support on the tendencies of breastfeeding rates in the city of Pelotas (RS), Brazil, from 1982 to 2004. J Pediatr (Rio J). 2008;84(6):560-564.

Manuscript received Feb 14 2008, accepted for publication Jun 062008.

doi:10.2223/JPED.1823 
objective of evaluating the impact of this support on breastfeeding (BF) rate trends, this study compares the breastfeeding frequencies of cohorts of children born before and after the MGRS.

\section{Methods}

The study sample consists of four cohorts of children born in 1982, 1993, 1997-1998 and 2004, the sampling methods for which have been published previously. ${ }^{9-13}$

The inclusion criteria for the 1997-1998 cohort (the MGRS cohort) were: residents of the city's urban area, born at full term ( 37 to 42 weeks), single birth, free from significant perinatal morbidity, non-smoking mother, maternal intention to breastfeed, and absence of economic restrictions (family income $\geq$ six times the minimum monthly wage). In addition to these criteria, mothers that, by 14 days after birth, had started smoking or had introduced cow's milk or infant formula into the child's diet were excluded.

Mothers enrolled in the MGRS study were given video cassettes and pamphlets on breastfeeding and were visited while breastfeeding by the breastfeeding support team, composed of three nurses supervised by a pediatrician specialized in lactation. The following topics were addressed: importance of EBF during the first 6 months of life, prevention and treatment of lactation problems, storage of breastmilk, risks of bottles and pacifiers and encouraging paternal participation. The first contact was made within 24 hours of birth. If necessary, additional visits were made and families were given the number of a 24-hour telephone service.

Pediatricians were asked to follow WHO feeding recommendations. They were given scientific articles on the subject and there was publicity in a newspaper regarding the importance of breastfeeding.

The impact of support on breastfeeding rates in the MGRS sample was widely publicized in the city, which led the city management to use material from this cohort, in a synthesized form, to train health professionals for the public health system in 2004. The healthcare team of one of the city's hospitals was also trained between 2002 and 2004 and, in 2004, this hospital was awarded the status of Baby-Friendly Hospital.

The analysis plan includes extraction of subsets from the 1982, 1993 and 2004 cohorts that meet the same inclusion criteria as the MGRS and comparing these four cohorts in terms of frequency of EBF and BF. Information on feeding patterns were obtained from follow-up sub-studies, and WHO criteria were adopted, ${ }^{12}$ defining children as on EBF if they were given nothing but breastmilk, direct from the breast or pumped, and no other liquid or food with the exception of drops or syrups for the administration of vitamins, minerals or medication; and children were defined as on BF if they were given any breastmilk, irrespective of whether or not they were receiving other foods.
The protocols of the studies were approved by the Research Ethics Committee at the Universidade Federal de Pelotas.

\section{Results}

In the study carried out in $1982,5,914$ children were included in a cohort, of which 4,934 were visited in 1984. In the 1993 cohort, there were 5,304 births, of which 644 of 655 randomly selected children were visited at 3 months. At 6 and 12 months, the sample selected to be visited comprised 1,460 children, and the percentage of losses was $6.6 \%$.

For the MGRS, a total of 4,801 mothers were interviewed during the hospital screening and 310 of these were enrolled in the study, 287 (92.6\%) of whom were followed up for 2 years. The 2004 cohorts included 4,231 live births. A total of 3,985 of these were followed to age 3 months and 3,907 were followed up to 12 months.

Table 1 illustrates the distribution across the cohort samples of the subsets that met the MGRS criteria. All families had incomes greater than six times the minimum monthly wage, as this was one of the inclusion criteria.

Based on the follow-up data, EBF rates at 1 and 3 months were compared for the cohorts from 1993, 1997-1998 and 2004. It was not possible to make this comparison with the 1982 cohort since this information was not collected. In 1993, only $26 \%$ of babies were on EBF by 1 month of age, in contrast with $40 \%$ in the $1997-1998$ cohort and $77 \%$ in 2004 . At 3 months, 16,19 , and $46 \%$ of babies were on EBF, respectively. By 6 months none of the children were on exclusive breastfeeding in any of the four studies.

BF frequencies are listed in Table 2. From 1982 to 1993 there were discrete increases in $\mathrm{BF}$ rates during the second year of life, although the increase in rates from the 1997-1998 cohort onwards was more marked, starting in the first month. At 6 months, 42 and $46 \%$ of babies were being breastfed in 1982 and 1993, respectively, whereas in the 1997-1998 and 2004 cohorts this percentage had risen to 64 and $68 \%$, respectively. At 12 months, $33 \%$ of the babies in the 1997-1998 cohort and 34\% of those in the 2004 cohort were still being given breastmilk, in contrast with only 15 and $22 \%$ of babies in the 1982 and 1993 cohorts, respectively.

\section{Discussion}

The primary objective of this study was to evaluate the effect of breastfeeding support offered as part of the MGRS on BF trends. Our results indicate that this support had a positive influence. Although there was practically no progress in breastfeeding rates during the years separating the first two cohorts, the increase by 1997-1998 was marked, especially in EBF rates during the first month. This increase was probably due to the support program, since during the years between 1993 and 1997-1998 cohorts no specific promotion campaigns were run in the city. Furthermore, this effect could 
Table 1 - Distribution of subsets meeting MGRS inclusion criteria, with socioeconomic, demographic, reproductive and nutritional characteristics (Pelotas, Brazil)

\begin{tabular}{|c|c|c|c|c|}
\hline & 1982 Cohort $(\%)$ & 1993 Cohort (\%) & MGRS (\%) & 2004 Cohort (\%) \\
\hline Characteristics & $(n=421)$ & $(n=561)$ & $(n=310)$ & $(n=317)$ \\
\hline \multicolumn{5}{|c|}{ Maternal educational level (full years in education) } \\
\hline$<10$ years & 23.3 & 33.2 & 33.6 & 12.9 \\
\hline $10-14$ years & 34.4 & 41.0 & 41.9 & 47.0 \\
\hline$\geq 15$ years & 42.3 & 25.9 & 24.5 & 40.1 \\
\hline \multicolumn{5}{|l|}{ Maternal age } \\
\hline$<20$ years & 3.8 & 8.6 & 11.0 & 5.7 \\
\hline $20-35$ years & 86.5 & 75.9 & 72.9 & 72.8 \\
\hline$\geq 35$ years & 9.7 & 15.5 & 16.1 & 21.5 \\
\hline \multicolumn{5}{|l|}{ Type of delivery } \\
\hline Vaginal & 57.2 & 50.3 & 46.1 & 24.6 \\
\hline Caesarean & 42.8 & 49.7 & 53.9 & 75.4 \\
\hline \multicolumn{5}{|l|}{ Primiparous } \\
\hline Yes & 37.8 & 43.7 & 49.0 & 52.1 \\
\hline No & 62.2 & 56.3 & 51.0 & 47.9 \\
\hline \multicolumn{5}{|l|}{ Sex of child } \\
\hline Male & 49.2 & 50.6 & 52.3 & 52.7 \\
\hline Female & 50.8 & 49.4 & 47.7 & 47.3 \\
\hline \multicolumn{5}{|l|}{ Birth weight } \\
\hline$<2.500 \mathrm{~g}$ & 2.1 & 1.3 & 1.9 & 3.2 \\
\hline$\geq 2.500 \mathrm{~g}$ & 97.9 & 98.7 & 98.1 & 96.8 \\
\hline
\end{tabular}

MGRS = Multicenter Growth Reference Study.

have been potentially even greater had the city's pediatricians followed WHO nutritional recommendations, since many of them continued to prescribe infant formula unnecessarily and to recommend complementary foods inappropriately.

Contrary to the expectation that once the MGRS was finished rates would fall, perhaps not back to the 1993 level, but to an intermediate level, a significant increase in EBF rates was observed in the 2004 cohort. This appears, at least in part, to be due to the wide dissemination that the MGRS received in the city, which directly involved municipal health authorities, since the support team's nurses were part of the municipal health professional workforce. After the study there was greater interest on the part of city management in training public network professionals so as to improve care. 
Table 2 - Prevalence (\%) of breastfeeding by age (Pelotas, Brazil)

\begin{tabular}{|c|c|c|c|c|c|c|}
\hline \multirow[b]{2}{*}{ Study } & \multicolumn{6}{|c|}{ Age } \\
\hline & 1 month & 3 months & 6 months & 9 months & 12 months & 24 months \\
\hline 1982 Cohort & 87 & 68 & 42 & 26 & 15 & 6 \\
\hline 1993 Cohort & 87 & 60 & 46 & 28 & 22 & 14 \\
\hline MGRS & 99 & 87 & 64 & 46 & 33 & 11 \\
\hline 2004 Cohort & 93 & 81 & 68 & 50 & 34 & 14 \\
\hline
\end{tabular}

MGRS = Multicenter Growth Reference Study.

Additionally, the team at one of the largest maternity units in the city was also trained, which involved professionals working at other health services. Furthermore, mothers enrolled in the support program probably transferred their knowledge to their communities, and many of these mothers had further children in subsequent years, including in 2004. A large proportion of the higher income mothers, who were selected for this comparison, did not use public health services. Notwithstanding, the majority of pediatricians who see children at privately or through health plans also work in the public sector, and were thus also trained.

A systematic review of the impact of interventions on BF duration showed that the most effective interventions combined information, guidance, and support, and that interventions of greater intensity and longer duration were also more successful. ${ }^{6}$ Another review showed that the impact of counseling on EBF rates is proportional to the number of counseling sessions attended by the mother. ${ }^{7}$ According to a recent review, individual counseling increases the chances of EBF during the first month by 3.4 -fold, and the chances at 6 months by 1.9 -fold. ${ }^{14}$

These results should be generalized with caution. For methodological reasons, families with less purchasing power were excluded. It is not possible, therefore, to assert that the population of lower socioeconomic status would behave in the same way. Nevertheless, if the less privileged population of Pelotas exhibit similar behavior to the population of a study carried out in the city of Porto Alegre (which is also in the state of Rio Grande do Sul), the impact of breastfeeding support found in the current study may be an underestimation. According to the Porto Alegre study, the greatest impact of a breastfeeding support intervention (the Baby Friendly Initiative) was seen among the population of lower socioeconomic status. $^{15}$

In conclusion, the present study has demonstrated that support for breastfeeding was important for the increasing trend in breastfeeding rates seen among the population of higher socioeconomic status in the city of Pelotas. Bearing in mind the importance of breastfeeding for reducing infant morbidity and mortality, promotion of this practice should be one of the health priorities of any nation, particularly in nations where breastfeeding rates are below recommended, as is the case in Brazil.

\section{References}

1. Jones G, Steketee RW, Black RE, Bhutta ZA, Morris SS; Bellagio Child Survival Study Group. How many child deaths can we prevent this year? Lancet. 2003;362:65-71.

2. Victora CG, Smith PG, Vaughan JP, Nobre LC, Lombardi C, Teixeira AM, et al. Evidence for protection by breast-feeding against infant deaths from infectious diseases in Brazil. Lancet. 1987;2:319-21.

3. César JA, Victora CG, Barros FC, Santos IS, Flores JA. Impact of breast feeding on admission for pneumonia during postneonatal period in Brazil: nested case-control study. BMJ. 1999;318: 1316-20.

4. Fifty-fourth World Health Assembly. Document A54/INF.DOC./4. Global strategy for infant and young child feeding: the optimal duration of exclusive breast-feeding. Geneva: World Health Organization (WHO); 2001.

5. Giugliani ER, Victora CG. Complementary Feeding of Young children in developing countries: a review of current scientific knowledge. World Health Organ 1998;1-44.

6. de Oliveira MI, Camacho LA, Tedstone AE. Extending breastfeeding duration through primary care: a systematic review of prenatal and postnatal interventions. J Hum Lact. 2001; $17: 326-43$

7. Albernaz E, Victora CG. Impact of face-to-face counseling on duration of exclusive breast-feeding: a review. Rev Panam Salud Publica. 2003;14:17-24.

8. Kramer MS, Chalmers B, Hodnett ED, Sevkovskaya Z, Dzikovich I, Shapiro S, et al; PROBIT Study Group (Promotion of Breastfeeding Intervention Trial). Promotion of Breastfeeding Intervention Trial (PROBIT): a randomized trial in the Republic of Belarus. JAMA. 2001;285:413-20.

9. WHO Multicentre Growth Reference Study Group. Enrolment and baseline characteristics in the WHO Multicentre Growth Reference Study. Acta Paediatrica Suppl. 2006;450:7-15. 
10. Victora CG, Barros FC. Cohort profile: the 1982 Pelotas (Brazil) birth cohort study. Inter J Epidemiol. 2006;35:237-42.

11. Victora CG, Barros FC, Tomasi E, Menezes AM, Horta BL, Weiderpass $E$, et al. Tendências e diferenciais na saúde materno-infantil: delineamento e metodologia das coortes de 1982 e 1993 de mães e crianças de Pelotas, Rio Grande do Sul. Cad Saude Publica. 1996;12 Supl 1:S7-S14.

12. Araújo CL Albernaz E, Tomasi E, Victora CG. Implementation of the WHO Multicentre Growth Reference Study in Brazil. Food Nutr Bull. 2004;25:S53-9.

13. Barros AJ, da Silva dos Santos I, Victora CG, Albernaz EP, Domingues MR, Timm IK, et al. The 2004 Pelotas birth cohort: methods and description. Rev Saude Publica. 2006;40:402-13.
14. Bhutta ZA, Ahmed T, Black RE, Cousens S, Dewey K, Giugliani E, et al. What works? Intervention for maternal and child undernutition and survival. Lancet. In press 2008.

15. Braun ML, Giugliani ER, Soares ME, Giugliani C, Oliveira AP, Danelon CM. Evaluation of the impact of the baby-friendly hospital initiative on rates of breastfeeding. Am J Publ Health. 2003;93:1277-9.

Correspondence:

Elaine Albernaz

Barão de Santa Tecla, 583/204

CEP 96010-140 - Pelotas, RS - Brazil

E-mail: zanrebla@terra.com.br 